\title{
The effects of ageing on the biomechanical properties of root dentine and fracture
}

\author{
Haiping Xu ${ }^{a}$, Qinghua Zheng ${ }^{a}$, Yingfeng Shao ${ }^{b, * *}$, Fan Song ${ }^{b}$, \\ Lan Zhang ${ }^{a}$, Qian Wang ${ }^{a}$, Dingming Huang ${ }^{c, *}$ \\ a State Key Laboratory of Oral Diseases, West China Hospital of Stomatology, Sichuan University, Chengdu 610041, \\ China \\ ${ }^{\mathrm{b}}$ The State Key Laboratory of Nonlinear Mechanics, Institute of Mechanics, Chinese Academy of Sciences, \\ Beijing 100190, China \\ ${ }^{\mathrm{C}}$ Department of Conservative Dentistry and Endodontics, West China School of Stomatology, Sichuan University, \\ Chengdu 610041, China
}

\section{A R T I C L E I N F O}

Article history:

Received 29 August 2013

Received in revised form

24 November 2013

Accepted 29 November 2013

Keywords:

Root fracture

Dentine

Ageing

Biomechanics

Nano-indentation

Finite element analysis

\begin{abstract}
A B S T R A C T
Objectives: Knowledge of the mechanical behaviour of root dentine can facilitate better understanding of spontaneous vertical root fracture (VRF), an age-related disease initiated mainly at the root apex. We tested the hypothesis that the biomechanical properties of root dentine change with ageing.

Methods: Sixteen human premolars were divided into "old" (17-30 years) and "young" (5080 years) groups. The elastic modulus, nano-hardness, micro-hardness, elemental contents, tubular density/area of root dentine in cervical, middle and apical root regions were evaluated using atomic force microscopy-based nano-indentation, Knoop indentation, scanning electron microscopy and energy dispersive X-ray spectroscopy, respectively. Results: The apical dentine showed a lower nano-hardness, a lower elastic modulus, a lower calcium content, a lower calcium-to-phosphorus ratio and a smaller tubular density/area than the cervical dentine in both age groups, whereas spatial differences in micro-hardness were observed only in old roots. Compared with young dentine, old dentine showed a greater hardness, a higher elastic modulus, a greater mineral content and a smaller tubular size in the cervical portion, whereas the age-induced changes in tubular density were insignificant. Finite element analysis revealed that due to its higher elastic modulus, old apical dentine has a higher stress level than young dentine.

Conclusions: The intrinsic material properties of root dentine have spatial variations, and they are altered by ageing. The higher stress level in old apical dentine may be one reason, if not the most important one, why spontaneous VRFs are more likely to occur in the elderly population.
\end{abstract}

(C) 2013 Elsevier Ltd. All rights reserved.

* Corresponding author at: 14\#, 3rd Section, Ren Min Nan Lu, West China School of Stomatology, Sichuan University, Chengdu, Sichuan 610041, China. Tel.: +86 28 85501439; fax: +86 2885582167 .

** Corresponding author. Tel.: +86 1082544089.

E-mail addresses: shaoyf@lnm.imech.ac.cn (Y. Shao), dingminghuang@163.com (D. Huang). 0300-5712/\$ - see front matter (C) 2013 Elsevier Ltd. All rights reserved. 


\section{Introduction}

Vertical root fracture (VRF), a longitudinal fracture line extending from the root canal to the periodontium, can involve both endodontically and non-endodontically treated teeth. ${ }^{1}$ Troubled by the poor prognoses of VRFs, many researchers have attempted to investigate the aetiology of VRF for early-stage prevention and to explore new therapies. Iatrogenic factors, such as tooth structural loss ${ }^{2}$ and the effects of restorative procedures, ${ }^{3}$ are considered to be the main causes of fractures after endodontic treatment. However, VRFs in non-endodontically treated teeth, known as spontaneous VRFs, have received little attention. Indeed, they have a high frequency in Chinese people, who constitute a population with a dietary pattern of chewing hard foods, ${ }^{4,5}$ and $40 \%$ of VRFs occur in non-endodontically treated teeth. ${ }^{6}$

Clinical studies have found that spontaneous VRFs always occur in severely attrited first molars. ${ }^{4}$ It is noteworthy that cracks initiate at the root apex and propagate coronally. ${ }^{4,5}$ On the one hand, stress might be concentrated at the apical area during mastication for root geometry; on the other hand, the intrinsic properties of the apex itself might constitute the weakest point of the root. ${ }^{6}$ However, to our knowledge, there has been no scientific research that has demonstrated the variations in mechanical behaviour of different portions of root materials and their effects on VRFs.

Dentine is the major constituent of the tooth root. Similar to most bio-mineralization materials, such as enamel and bone, dentine has a hierarchical structure, in which collagen and apatite molecules cross each other on a nano-scale. Subsequently, these composites organize into a microscopic morphology, forming tubules with different sizes and densities. The specific arrangement and order of the nano- and micro-structures produce a macroscopic anisotropy with certain functional behaviours. ${ }^{7}$ The properties of coronal dentine have been researched in many studies, ${ }^{8,9}$ but root dentine, which is closely related to the fracture behaviour of the root, has not been comprehensively researched.

Previous research has revealed that dentine undergoes gradual spatial transition in its material properties. ${ }^{10}$ In the crown, the hardness and elastic modulus of intertubular dentine decrease towards the dentino-enamel junction, ${ }^{8}$ which has been deduced to be related to the degree of mineralization. ${ }^{11}$ In the root, a decreasing trend in mineral content from the cervical dentine to the apical dentine has been found. ${ }^{12}$ Hence, the mechanical properties of root dentine are suspected to vary with location.

In addition, spontaneous VRFs tend to occur mainly in patients older than 40 years old. ${ }^{1,5}$ Ageing problems and agerelated changes in the mechanical behaviour of dentine have attracted attention. In coronal dentine, there is a significant reduction in the strength, energy required to fracture and fracture toughness with increasing age. ${ }^{13-15}$ However, little research has been undertaken on root dentine until now, except for Kinney et al., ${ }^{12}$ and Porter et al., ${ }^{16}$ who found that the mineral concentrations and crystallite size of root dentine changed with age. Whether there are changes in the mechanical properties of aged root dentine is unclear.
Because material properties can vary with spatial scales, root dentine should be studied at all hierarchical levels. ${ }^{17}$ Microscopic tests are technically difficult to perform due to the limited volume of human root dentine. In addition, dentinal tubules are known to vary in diameter, which might cause different properties among rectangular beam specimens. Thus, the indentation technique has been increasingly applied in small areas of potentially anisotropic composite materials, such as dentine.

To investigate the changes in the mechanical properties of root dentine associated with ageing and the effects of ageing on VRFs, Knoop indentations and atomic force microscopy (AFM)-based nano-indentations were utilized. The corresponding tubular density/area and elemental composition were examined by scanning electron microscopy (SEM) and energy dispersive X-ray spectroscopy (EDS). We hypothesized that the biomechanical function of the root would change with age.

\section{Materials and methods}

\subsection{Specimen preparation}

Human mandibular premolars with single roots and vital pulp were obtained following a protocol approved by the Ethics Committee of the West China Hospital of Stomatology. The collection of teeth did not change the course of any patient's treatment plan, including orthodontic treatment, periodontal treatment, and so on. The teeth were sterilized by gamma radiation ${ }^{18}$ and were stored in Hanks' balanced salt solution (HBSS) at $4{ }^{\circ} \mathrm{C}$ before examination. ${ }^{19}$ All teeth were integral and examined using a stereomicroscope (SMZ1000, Nikon Corp., Tokyo, Japan) to ascertain the absence of any root fractures or craze lines. The collected teeth were divided into "young" (17-30 years old, $n=8$ ) and "old" (50-80 years old, $n=8$ ) groups. ${ }^{13}$ The average age and the standard deviation of the young and old groups were $24 \pm 3$ and $64 \pm 7$ years, respectively. The crowns were removed at the cemento-enamel junction, using a water-cooled diamond saw (Struers Minitom, Struers, Copenhagen, Denmark). The roots were then sectioned bucco-lingually through the centre of the root canal (Fig. 1A). The mesio-segments were embedded and polished using a series of SiC papers to 4000 grit and were finished with diamond pastes (1- and $0.25-\mu \mathrm{m}$ ). The specimens were then cleaned ultrasonically and were maintained in HBSS until used.

\subsection{AFM-based nano-indentation}

Nano-indentation was performed using a Nanoscope III AFM (Digital Instruments, Santa Barbara, CA, USA), modified with a Triboscope system and a Berkovich diamond indenter (Hysitron Inc., Minneapolis, MN, USA) under wet conditions. Measurements were obtained at the cervical, middle and apical root regions along the centre of the root canal (Fig. 1A). Each region was tested at two sites. For each site, six indentations, approximately $10 \mu \mathrm{m}$ apart, were performed in intertubular dentine. The maximum load was $2500 \mu \mathrm{N}$ and was held for $3 \mathrm{~s}$, with loading/unloading 


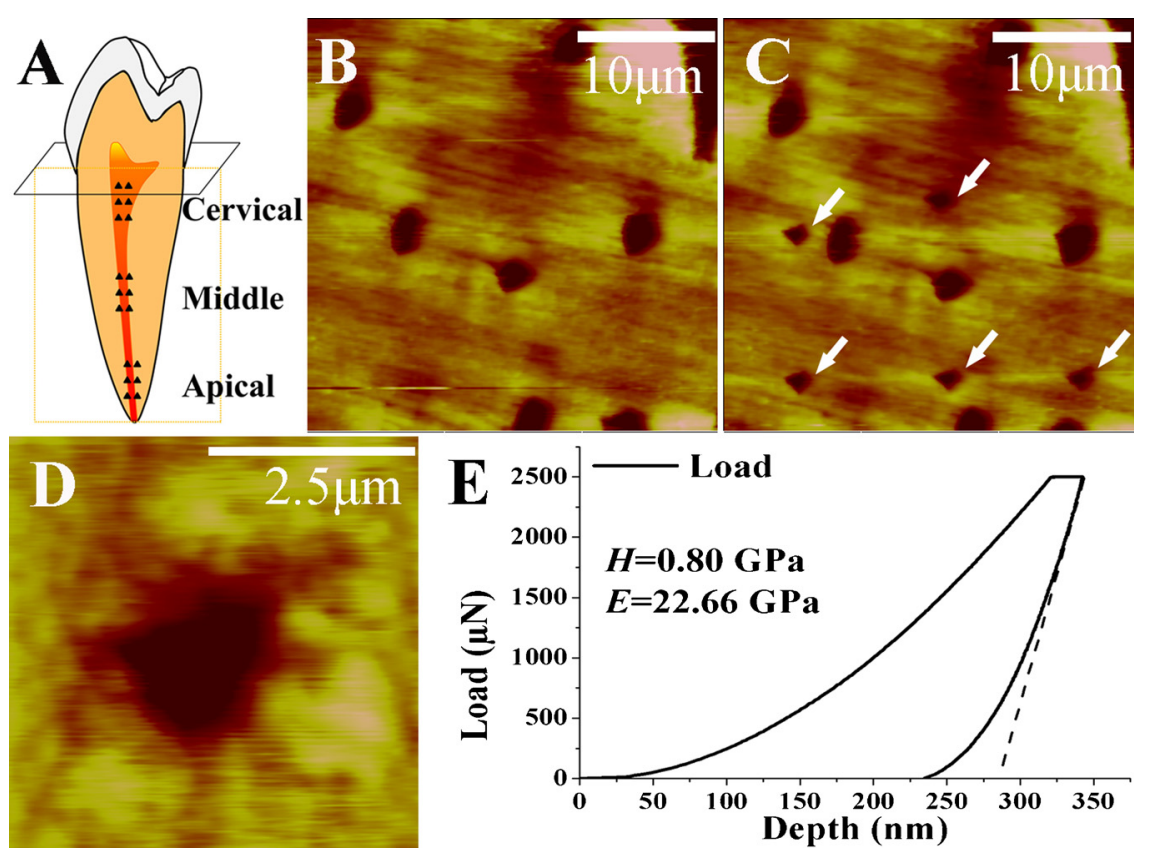

Fig. 1 - (A) Schematic illustration of a premolar showing specimen preparation and test locations. AFM images collected before (B) and after (C) nano-indentations (30 $\mathrm{m} \times 30 \mu \mathrm{m}$; arrows indicate indentations). (D) A typical nano-indentation $(5 \mu \mathrm{m} \times 5 \mu \mathrm{m})$ and $(E)$ the corresponding load-displacement curve.

for $4 \mathrm{~s}$ each. The elastic modulus, $E$, and hardness, $H$, were quantified from the load-displacement curve according to the following equations ${ }^{20}$ :

$E=\frac{\sqrt{\pi}}{2 \sqrt{a}} \times S$,

$H=\frac{F_{\max }}{a}$

where $S$ is defined as the slope of the unloading curve near the maximum load, ${ }^{21} a$ is the projected indentation contact area, and $F_{\text {max }}$ represents the maximum force (Fig. 1E). Because the clarity of the indenter's shape reflects the reliability of the tested mechanical property values, AFM images were obtained before and after indentations to ensure they were uniform, well-defined and within the intertubular dentine (Fig. 1B-D). Calibration was performed using a fused silica standard.

\subsection{Knoop micro-indentation}

Knoop hardness (HK) was measured on a micro-hardness tester (Duramin-2/-1, Struers, Copenhagen, Denmark) with a Knoop diamond indenter. A 25-g load was applied at the three levels with a dwell time of $15 \mathrm{~s}$. Ten indentations were determined at each location at $50-\mu \mathrm{m}$ intervals. HK (GPa) was determined as ${ }^{10}$ :

$H K=0.014229 \times \frac{F}{d^{2}}$,

where $F$ is the force $(N)$, and $d$ is the length of the long diagonal of the indentation $(\mathrm{mm})$.

\subsection{SEM-EDS test}

All of the specimens were fixed in $2.5 \%$ glutaraldehyde and were dehydrated through an ascending series of ethanol (30$100 \%$ ). Specimens were mounted on aluminium stubs, desiccated, sputter-coated with gold and observed under SEM (Inspect F, FEI, Eindhoven, Netherlands) equipped with EDS (Inca, Oxford Instruments, Oxford, UK). The same three locations were evaluated.

SEM photomicrographs were analyzed using Image-pro PLUS software, version 6.0 (Media Cybernetics, Silver Spring, MD, USA). Tubular density (tubules $/ \mathrm{mm}^{2}$ ) was calculated at $\times 1000$ magnification, and tubular area at $\times 8000$ magnification with 10 tubules was measured for each photomicrograph.

The calcium (Ca), phosphorus (P) content and the Ca-to-P ratio of intertubular dentine were analyzed with an EDS detector using a measurement area of $1 \mu \mathrm{m} \times 1 \mu \mathrm{m}$. For each location, five set scans were obtained.

\subsection{Statistics}

Results were subjected to one-way ANOVA. Differences among locations within one specimen were analyzed by $q^{-}$ test. All of the tests were two-sided, and the significance level was 0.05 .

\subsection{Finite element (FE) analysis}

To investigate the effects of age on the von Mises stress distribution in teeth, an axisymmetric model of a mandibular premolar, which included alveolar bone, was analyzed with ANSYS software. The FE model comprised pulp, dentine, 
Table 1 - Material properties of the isotropic materials

used for the finite element analysis.

\begin{tabular}{|c|c|c|}
\hline Material & $\begin{array}{c}\text { Elastic } \\
\text { modulus (GPa) }\end{array}$ & $\begin{array}{l}\text { Poisson's } \\
\text { coefficient }\end{array}$ \\
\hline Enamel $^{22}$ & 82.5 & 0.33 \\
\hline Pulp ${ }^{23}$ & $2 \times 10^{-3}$ & 0.45 \\
\hline Periodontal ligament ${ }^{23,24}$ & $68.9 \times 10^{-3}$ & 0.45 \\
\hline Cortical bone $e^{23,24}$ & 13.7 & 0.30 \\
\hline Sponge bone ${ }^{23,24}$ & 1.37 & 0.30 \\
\hline
\end{tabular}

periodontal ligament, cortical bone and sponge bone, as shown in Fig. 3A. As a boundary condition, no displacement was allowed for the nodes along the bottom end lines of the models, and a vertical load of $100 \mathrm{~N}$ was applied at the centre of the crown.

All of the materials were considered to be homogeneous, isotropic and linear elastic, and their properties are reported in Table $1 .{ }^{22-24}$ Note that the elastic modulus of dentine in the cervical, middle and apical locations of both groups was obtained from the nano-indentation measurement.

\section{Results}

\subsection{Mechanical properties from nano- and micro- indentation}

Table 2 shows that the nano-hardness and elastic modulus of both old and young dentine decreased from the cervical root to the apex $(P<0.05)$. A declining trend in micro-hardness towards the apex was found in old dentine $(P<0.05)$, which was not observed in young dentine. The differences in nanohardness, elastic modulus and micro-hardness between age groups were significant at the cervical region $(P<0.05)$ and insignificant at the lower areas.

\section{2. $\mathrm{Ca}$ and $\mathrm{P}$ contents}

Similar to the change in nano-hardness, the Ca content (wt\%) and Ca-to-P ratio decreased towards the apex regardless of age, whereas the age-induced increases in Ca content and Cato-P ratio were only statistically significant at the cervical third

Table 2 - Nano-hardness (GPa), elastic modulus (GPa) and Knoop micro-hardness (GPa) of old and young dentine (mean + SD) from nano- and micro-indentation.

\begin{tabular}{|c|c|c|c|c|}
\hline & & Cervical third & Middle third & Apical third \\
\hline \multirow[t]{3}{*}{ Nano-hardness } & Old & $0.96 \pm 0.02(\mathrm{~A})$ & $0.64 \pm 0.08(\mathrm{~B})$ & $0.56 \pm 0.11(\mathrm{~B})$ \\
\hline & Young & $0.77 \pm 0.07(a)$ & $0.62 \pm 0.04(b)$ & $0.55 \pm 0.04(\mathrm{~b})$ \\
\hline & & $P<0.05$ & $P>0.05$ & $P>0.05$ \\
\hline \multirow[t]{3}{*}{ Elastic modulus } & old & $24.47 \pm 1.01(\mathrm{~A})$ & $19.99 \pm 2.43(\mathrm{~A}, \mathrm{~B})$ & $17.65 \pm 3.15(\mathrm{~B})$ \\
\hline & Young & $20.11 \pm 1.90(a)$ & $18.03 \pm 0.79(a, b)$ & $16.45 \pm 0.24(b)$ \\
\hline & & $P<0.05$ & $P>0.05$ & $P>0.05$ \\
\hline \multirow[t]{3}{*}{ Knoop hardness } & old & $0.69 \pm 0.06(\mathrm{~A})$ & $0.59 \pm 0.12(\mathrm{~A}, \mathrm{~B})$ & $0.49 \pm 0.13(\mathrm{~B})$ \\
\hline & Young & $0.54 \pm 0.11(\mathrm{a})$ & $0.54 \pm 0.07(a)$ & $0.50 \pm 0.07(\mathrm{a})$ \\
\hline & & $P<0.05$ & $P>0.05$ & $P>0.05$ \\
\hline
\end{tabular}

Different letters in parentheses indicate significant differences in location $(P<0.05)$. $P<0.05$ means significant difference between young and old, while $P>0.05$ means no significant difference between age groups.

Table 3 - Ca, P contents (wt\%) and Ca-to-P ratio, tubular density (tubules $/ \mathrm{mm}^{2}$ ) and area ( $\mu \mathrm{m}^{2}$ ) of old and young dentine (mean + SD).

\begin{tabular}{|c|c|c|c|c|}
\hline & & Cervical third & Middle third & Apical third \\
\hline \multirow[t]{3}{*}{$\mathrm{Ca}$} & Old & $51.05 \pm 5.79(\mathrm{~A})$ & $41.81 \pm 5.63(\mathrm{~B})$ & $33.28 \pm 6.91(C)$ \\
\hline & Young & $44.38 \pm 2.79(a)$ & $35.97 \pm 4.21(\mathrm{~b})$ & $27.26 \pm 1.48(c)$ \\
\hline & $P$ & $P<0.05$ & $P>0.05$ & $P>0.05$ \\
\hline \multirow[t]{3}{*}{$\mathrm{P}$} & old & $16.77 \pm 0.93(\mathrm{~A})$ & $16.84 \pm 0.78(\mathrm{~A})$ & $16.62 \pm 0.77(\mathrm{~A})$ \\
\hline & Young & $17.94 \pm 2.32(a)$ & $17.34 \pm 1.89(\mathrm{a})$ & $17.54 \pm 3.31(a)$ \\
\hline & & $P>0.05$ & $P>0.05$ & $P>0.05$ \\
\hline \multirow[t]{3}{*}{ Ca-to-P ratio } & old & $3.05 \pm 0.35(\mathrm{a})$ & $2.48 \pm 0.32(b)$ & $2.02 \pm 0.52(b)$ \\
\hline & Young & $2.51 \pm 0.38(\mathrm{a})$ & $2.12 \pm 0.48(a, b)$ & $1.62 \pm 0.47(b)$ \\
\hline & & $P<0.05$ & $P>0.05$ & $P>0.05$ \\
\hline \multirow[t]{3}{*}{ Tubular density $\left(\times 10^{3}\right)$} & old & $24.95 \pm 5.79(\mathrm{~A})$ & $19.63 \pm 5.40(\mathrm{~A}, \mathrm{~B})$ & $11.00 \pm 7.64(\mathrm{~B})$ \\
\hline & Young & $27.36 \pm 5.61(\mathrm{a})$ & $19.77 \pm 5.46(\mathrm{~b})$ & $12.02 \pm 5.16(\mathrm{c})$ \\
\hline & & $P>0.05$ & $P>0.05$ & $P>0.05$ \\
\hline \multirow[t]{3}{*}{ Tubular area } & old & $3.52 \pm 0.67(\mathrm{~A})$ & $3.09 \pm 0.61(\mathrm{~A})$ & $1.91 \pm 0.83(\mathrm{~B})$ \\
\hline & Young & $4.72 \pm 0.89(a)$ & $3.74 \pm 0.85(\mathrm{a})$ & $2.01 \pm 0.82(b)$ \\
\hline & & $P<0.05$ & $P>0.05$ & $P>0.05$ \\
\hline
\end{tabular}

Different letters in parentheses indicate significant differences in location $(P<0.05) . P<0.05$ means significant difference between young and old, while $P>0.05$ means no significant difference between age groups. 

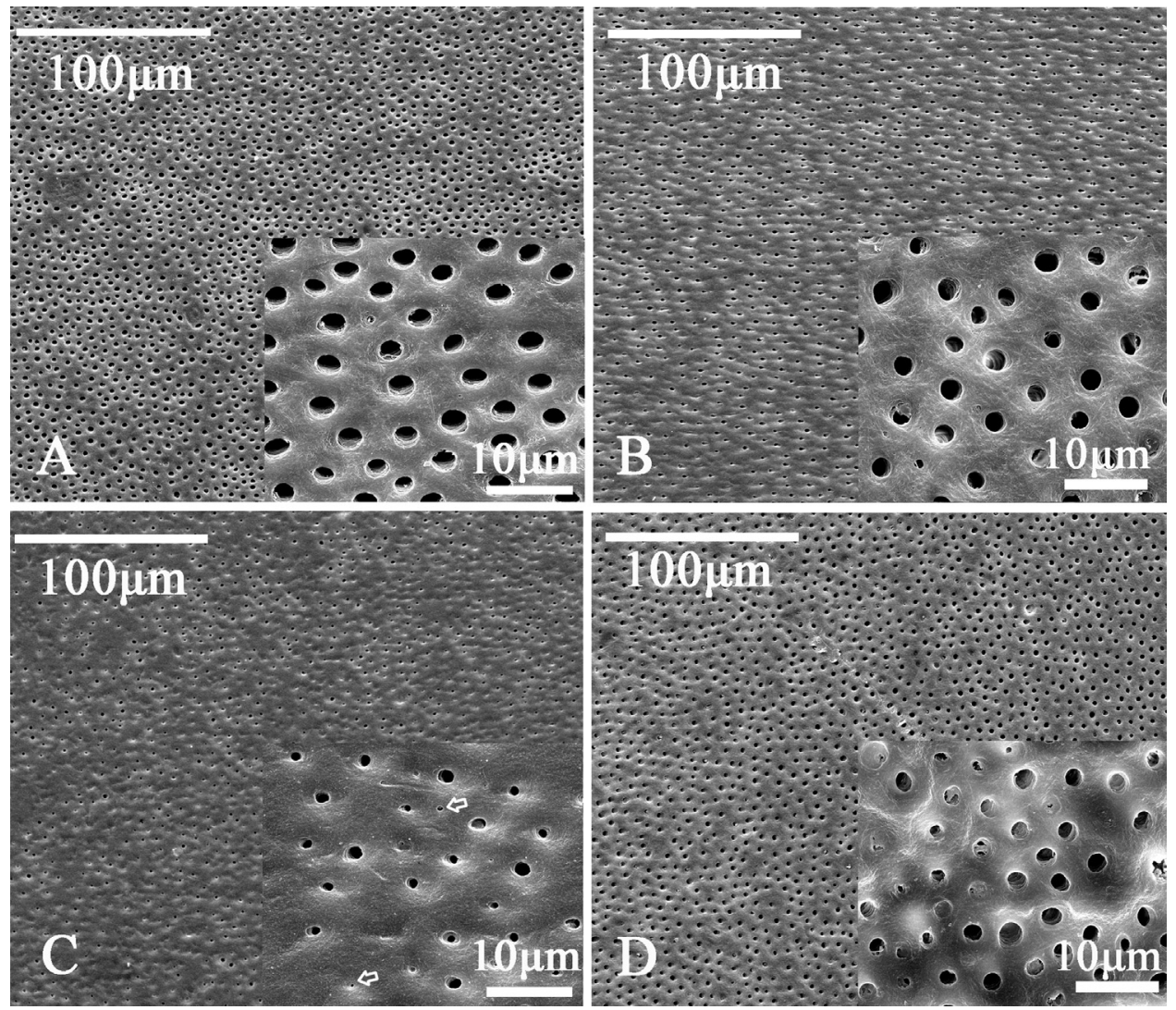

Fig. 2 - (A-C) Low- $(\times 1000)$ and high-resolution $(\times 8000$, insets) SEM micrographs of the radicular dentine: the number of dentinal tubules decreased, and the lumina became smaller gradually, from (A) cervical, (B) towards middle and apical (C) thirds. The size of the lumen became uneven, with some fine branches (hollow arrows) at the apex (C). (D) One specimen from old cervical root showed the tubules become smaller than that in young dentine resulted from the deposition of minerals within the lumina.

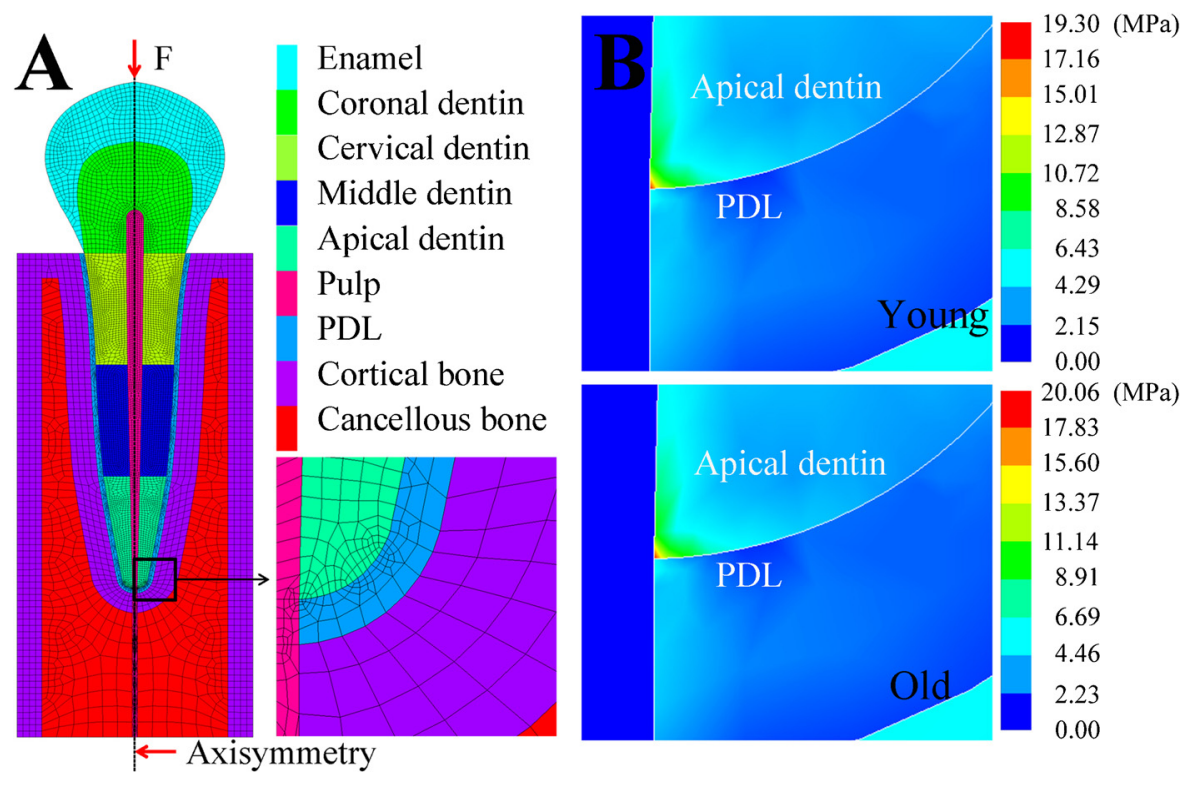

Fig. 3 - (A) The axisymmetric finite element model of a tooth and its partial enlargement, where PDL indicates the periodontal ligament. (B) Contour maps of von Mises stress in young and old apical roots with applied load. 
$(P<0.05)$. In terms of $P$ content, there was no significant change as a function of location or ageing (Table 3 ).

\subsection{Tubular density and area}

Fig. 2 illustrates the micromorphology of the gradually changed root dentine. Both tubular density and area decreased progressively towards the apex, regardless of age $(P<0.05$, Table 3$)$. In the apex, the tubular size became uneven, with some fine branches (Fig. 2C). The tubular area of old dentine became smaller than that of young dentine at the cervical regions $(P<0.05)$, and the diminution was insignificant at lower regions. No age-related difference was found for tubular density.

\subsection{Finite element analysis}

The contour maps of the von Mises stress, in the cases of young and old apical roots with applied loads, are shown in Fig. 3B. The von Mises stresses were distributed mainly inside the dentine; in particular, the highest values were found to be located around the root tip. The maximum von Mises stress of old apical dentine was 3.9\% higher than that of young dentine.

\section{Discussion}

The nano-hardness and elastic modulus obtained in this study ( $\mathrm{H}=0.55-0.96 \mathrm{GPa}, E=16.45-24.47 \mathrm{GPa})$ were consistent with the reported values from nano-indentation measurements. ${ }^{25}$ These mechanical properties of root intertubular dentine deceased from the cervical dentine to the apical dentine in both age groups. The spatial variations in properties could be primarily attributed to chemical variation ${ }^{26}$ because our complementary EDS analysis of intertubular dentine revealed synchronous decreases in Ca content and Ca-to-P ratio in the coronoapical direction. The old intertubular dentine was found to have significantly higher nano-hardness and a higher elastic modulus, accompanied by a higher $\mathrm{Ca}$ concentration and higher Ca-to-P ratio than young dentine at the cervical root. In crown, old intertubular dentine was found to be harder than young one, ${ }^{9,27}$ indicating that intertubular dentine might be sclerosed with ageing. In root dentine, we found similar change, suggesting that there might be an accumulation of mineral salts in the root intertubular dentine with ageing.

The micro-hardness also deceased from the cervical dentine to the apical dentine in the old dentine group, whereas the decreased rate was somewhat lower than the nano-hardness. In addition, in the young roots, no obvious differences were observed among the locations. As reported previously, ${ }^{28}$ we found that the cervical dentine tubules were larger and denser than those in the lower portions in both age groups. Micro-indentation at the cervix involves more empty space of tubules and less intertubular dentine than at the apex, which causes micro-hardness to decrease more pronouncedly in the cervical dentine than in the apical dentine. ${ }^{10,29}$ Thus, compared with nano-hardness, the spatial variation in micro-hardness is compromised by spatial distribution in the tubules, causing the decreasing tendency in micro-hardness to diminish (in old roots) or even disappear (in young roots). Similar to nano-hardness, the spatial distribution of micro-hardness in dentine agrees well with the mineral distributions measured in root dentine, which involve both root intertubular dentine and tubules. ${ }^{12}$ Tubules in old dentine were observed to be smaller than those in young dentine in cervical roots because the minerals deposited into the tubular lumina and occluded the orifices with ageing, as shown by our SEM examination (Fig. 2D). The intratubular minerals are chemically similar to the surrounding intertubular minerals, and intratubular dentine has been reported to have higher hardness than intertubular dentine. ${ }^{30}$ In addition, old intertubular dentine was found to have higher nano-hardness than young dentine at the root. As a result, the micro-hardness of the old dentine was significantly higher than that of the young dentine in cervical roots.

Based on the above-mentioned results, we conclude that these age-induced microstructural changes cause spatial variations in the intrinsic material properties of root dentine. Thus, ageing could play an important role in the occurrence of spontaneous VRFs. According to FE simulation, old apical dentine presented a maximum von Mises stress 3.9\% higher than that of young dentine, which have been due to old dentine having a relatively higher elastic modulus than young dentine. Compared with young apical dentine, old apical dentine, with the higher stress level and the age-related reduction in the strength of root dentine, ${ }^{31}$ could have a higher likelihood of damage occurrence. ${ }^{32}$ Moreover, although a study on the effects of ageing on the fracture of apical dentine has not been conducted, it is expected that there would be a significant reduction in fracture toughness. ${ }^{31}$ Thus, due to a high stress level, a possible low strength and an expected low fracture toughness, old roots may become more susceptible to fractures than young roots.

\section{Conclusions}

In conclusion, the intrinsic material properties of root dentine have spatial variations, and they are altered by ageing. In aged roots, the mineral accretion in intertubular dentine provides the higher nano-hardness and higher elastic modulus, and the sclerosed intertubular dentine and new intratubular minerals together account for the higher micro-hardness value. Finite element analysis suggests that old apical dentine has a higher stress level than young dentine, which may be one reason, if not the most important one, why spontaneous VRFs are more likely to occur in the elderly population.

\section{Acknowledgments}

This study was supported by the National Natural Science Foundation of China (11272226, 11072252, 11023001 and 11102208). All of the authors declare that they have no conflicts of interest.

\section{R E F E R E N C E S}

1. Zou X, Liu D, Yue L, Wu M. The ability of cone-beam computerized tomography to detect vertical root fractures 
in endodontically treated and nonendodontically treated teeth: a report of 3 cases. Oral Surgery Oral Medicine Oral Pathology Oral Radiology and Endodontology 2011;111:797-801.

2. Cheron RA, Marshall SJ, Goodis HE, Peters OA. Nanomechanical properties of endodontically treated teeth. Journal of Endodontics 2011;37:1562-5.

3. Shemesh H, Bier C, Wu MK, Tanomaru-Filho M, Wesselink P. The effects of canal preparation and filling on the incidence of dentinal defects. International Endodontic Journal 2009;42:208-13.

4. Wang P, Su L. Clinical observation in 2 representative cases of vertical root fracture in nonendodontically treated teeth. Oral Surgery Oral Medicine Oral Pathology Oral Radiology and Endodontology 2009;107:e39-42.

5. Tang L, Zhou X, Wang Y, Zhang L, Zheng Q, Huang D. Detection of vertical root fracture using cone beam computed tomography: report of two cases. Dental Traumatology 2011;27:484-8.

6. Chan CP, Lin CP, Tseng SC, Jeng JH. Vertical root fracture in endodontically versus nonendodontically treated teeth: a survey of 315 cases in Chinese patients. Oral Surgery Oral Medicine Oral Pathology Oral Radiology and Endodontology 1999;87:504-7.

7. Katz JL, Misra A, Spencer P, Wang Y, Bumrerraj S, Nomura T, et al. Multiscale mechanics of hierarchical structure/ property relationships in calcified tissues and tissue/ material interfaces. Materials Science and Engineering A Structural Materials Properties Microstructure and Processing 2007;27:450-68.

8. Tesch W, Eidelman N, Roschger P, Goldenberg F, Klaushofer K, Fratzl P. Graded microstructure and mechanical properties of human crown dentin. Calcified Tissue International 2001;69:147-57.

9. Senawongse P, Otsuki M, Tagami J, Mjör I. Age-related changes in hardness and modulus of elasticity of dentine. Archives of Oral Biology 2006;51:457-63.

10. Brauer DS, Hilton JF, Marshall GW, Marshall SJ. Nano- and micromechanical properties of dentine: investigation of differences with tooth side. Journal of Biomechanics 2011;44:1626-9.

11. Angker L, Nockolds C, Swain MV, Kilpatrick N. Correlating the mechanical properties to the mineral content of carious dentine-a comparative study using an ultra-micro indentation system (UMIS) and SEM-BSE signals. Archives of Oral Biology 2004;49:369-78.

12. Kinney JH, Nalla RK, Pople JA, Breunig TM, Ritchie RO. Agerelated transparent root dentin: mineral concentration, crystallite size, and mechanical properties. Biomaterials 2005;26:3363-76.

13. Arola D, Reprogel R. Effects of aging on the mechanical behavior of human dentin. Biomaterials 2005;26:4051-61.

14. Koester KJ, Ager III JW, Ritchie RO. The effect of aging on crack-growth resistance and toughening mechanisms in human dentin. Biomaterials 2008;29:1318-28.

15. Nazari A, Bajaj D, Zhang D, Romberg E, Arola D. Aging and the reduction in fracture toughness of human dentin. Journal of the Mechanical Behavior of Biomedical Materials 2009;2:550-9.

16. Porter AE, Nalla RK, Minor A, Jinschek JR, Kisielowski C, Radmilovic V, et al. A transmission electron microscopy study of mineralization in age-induced transparent dentin. Biomaterials 2005;26:7650-60.

17. Fratzl P, Weinkamer R. Nature's hierarchical materials. Progress in Materials Science 2007;52:1263-334.

18. Brauer DS, Saeki K, Hilton JF, Marshall GW, Marshall SJ. Effect of sterilization by gamma radiation on nanomechanical properties of teeth. Dental Materials 2008;24:1137-40.

19. Habelitz S, Marshall Jr GW, Balooch M, Marshall SJ. Nanoindentation and storage of teeth. Journal of Biomechanics 2002;35:995-8.

20. Doerner M, Nix W. A method for interpreting the data from depth-sensing indentation instruments. Journal of Materials Research 1986;1:601-9.

21. Oliver WC, Pharr GM. Improved technique for determining hardness and elastic modulus using load and displacement sensing indentation experiments. Journal of Materials Research 1992;7:1564-83.

22. Farah J, Powers J, Dennison J, Craig R, Spencer J. Effects of cement bases on the stresses and deflections in composite restorations. Journal of Dental Research 1976;55:115-20.

23. Coelho CS, Biffi JC, Silva GR, Abrahão A, Campos RE, Soares $C J$, et al. Finite element analysis of weakened roots restored with composite resin and posts. Dental Materials Journal 2009;28:671-8

24. Ren L, Wang W, Takao Y, Chen Z. Effects of cementumdentine junction and cementum on the mechanical response of tooth supporting structure. Journal of Dentistry 2010;38:882-91.

25. Kinney J, Marshall S, Marshall G. The mechanical properties of human dentin: a critical review and re-evaluation of the dental literature. Critical Reviews in Oral Biology \& Medicine 2003;14:13-29.

26. Sakoolnamarka R, Burrow M, Swain M, Tyas M. Microhardness and Ca P ratio of carious and Carisolv ${ }^{\mathrm{TM}}$ treated caries-affected dentine using an ultra-microindentation system and energy dispersive analysis of X-rays-a pilot study. Australian Dental Journal 2005;50:246-50.

27. Zheng L, Nakajima M, Higashi T, Foxton RM, Tagami J. Hardness and Young's modulus of transparent dentin associated with aging and carious disease. Dental Materials Journal 2005;24:648-53.

28. Carrigan PJ, Morse DR, Furst ML, Sinai IH. A scanning electron microscopic evaluation of human dentinal tubules according to age and location. Journal of Endodontics 1984;10:359-63.

29. Pashley D, Okabe A, Parham P. The relationship between dentin microhardness and tubule density. Dental Traumatology 1985;1:176-9.

30. Balooch M, Demos S, Kinney J, Marshall G, Balooch G, Marshall S. Local mechanical and optical properties of normal and transparent root dentin. Journal of Materials Science Materials in Medicine 2001;12:507-14.

31. Arola D, Ivancik J, Majd H, Fouad A, Bajaj D, Zhang XY, et al. Microstructure and mechanical behavior of radicular and coronal dentin. Endodontic Topics 2012;20:30-51.

32. Pegoretti A, Fambri L, Zappini G, Bianchetti M. Finite element analysis of a glass fibre reinforced composite endodontic post. Biomaterials 2002;23:2667-82. 